\title{
PENGARUH INTENSITAS PENGGUNAAN INTERNET TERHADAP PRESTASI BELAJAR SISWA DI SMA NEGERI 13 KERINCI
}

\author{
Ayu Permata $\operatorname{Sari}^{1}$ dan Novera Utami ${ }^{2}$ \\ (Prodi Bimbingan dan Konseling STKIP Muhammadiyah Sungai Penuh) \\ Email: ayusoemantri@gmail.com
}

\begin{abstract}
ABSTRAK
Internet saat ini tidak bisa dipisahkan dari kehidupan manusia modren. Saat ini para siswa selalu mengunakan internet baik itu melalui komputer maupun gadget yang mereka miliki. Diyakini bahwa internet memiliki pengaruh positif dan negatif bagi setiap penggunanya, lalu bagaimana dengan siswa? apakah penggunaan internet bagi siswa memiliki dampak positif ataupun negatif terhadap hasil belajar. Penelitian ini bertujuan untuk menguji hal tersebut, apakah terdapat pengaruh intensitas penggunaan internet dengan hasil belajar siswa. Penelitian ini menggunakan metode deskriptif korelasional dengan populasi seluruh siswa SMA Negeri 13 Kerinci tahun ajaran 2017/2018 yang berjumlah 284 siswa yan memiliki perbedaan jenis kelamin, strata kelas dan penghasilan orang tua (Heterogen), sampel penelitian diambil menggunakan teknik Proportional Random Sampling dengan tingkat kesalahan 0,05 sehingga sampel menjadi 166 orang. Angket yang digunakan untuk melihat intensitas belajar mengunakan angket dengan skala likert dengan reliabel 0,888 sebanyak 22 butir dan untuk hasil belajar dilihat dari nilai tengah semester siswa. Analisis data menggunakan rumus koralasi. Hasil penelitian menunjukan bahwa intensitas penggunaan internet pada siswa tergolong tinggi (61,21\%) dan sedang (38,78\%). Untuk prestasi belajar siswa rata-rata siswa adalah 68,94 yang masih tergolong rendah dan berada dibawah standar. Uji hipotesis menunjukan adanya pengaruh intensitas penggunaan internet terhadap prestasi belajar siswa di SMA Negeri 13 Kerinci, dengan besar pengaruhnya 14,1\%. Implikasi dari penelitian ini dapat digunakan oleh pihak sekolah agar dapat membuat bebrapa seminar tentang penggunaan internet yang positif pagi siswa agar intrnet dapat digunakan oleh siswa dalam belajar dan meningkatkan hasil belajar siswa SMA Negeri 13 Kerinci.
\end{abstract}

\section{Kata Kunci: Intensitas Penggunaan Internet, Prestasi Belajar}

\section{THE EFFECT INTENSITY OF INTERNET USE ON STUDENT LEARNING ACHIEVEMENT IN STATE HIGH SCHOOL 13 KERINCI}

\begin{abstract}
The internet today is inseparable from modern human life. At present students always use the internet either through computers or gadgets that they have. It is believed that the internet has positive and negative influences for every user, then what about students? whether the use of the internet for students has a positive or negative impact on learning outcomes. This study aims to test this, whether there
\end{abstract}


is an effect of the intensity of internet use with student learning outcomes. This study used a descriptive correlational method with a population of all students of the High School 13 Kerinci in the 2017/2018 academic year, which amounted to 284 students who had differences in gender, class strata and income of parents (heterogeneous). 0.05 so that the sample becomes 166 people. Questionnaire used to see the intensity of learning using a questionnaire with a Likert scale with a reliable 0.888 as many as 22 items and for learning outcomes seen from the midterm scores of students. Data analysis using the correlation formula. The results showed that the intensity of internet use in students was classified as high (61.21\%) and moderate (38.78\%). For student learning achievement the average student is 68.94 which is still relatively low and under the standard. Hypothesis testing shows the influence of the intensity of internet use on student achievement in Kerinci Public High School, with a magnitude of 14.1\%. The implications of this study can be used by the school to be able to make several seminars on the positive use of the internet in the morning so that the internet can be used by students in learning and improve the learning outcomes of students of High School 13 Kerinci.

\section{Keywords: Intensity of Using the Internet, Learning Achievement}

\section{PENDAHULUAN}

Di abad ke 21 ini perkembangan bidang ilmu pengetahuan dan teknologi meningkat sangat pesat, yang memberikan banyak perubahan dalam kehidupan manusia termasuk dalam bidang pendidikan. Menurut Deni (2015: 5), Pengembangan pendidikan berbasis teknologi setidaknya memberikan dua keuntungan, yaitu "Pertama, sebagai pendorong komunitas pendidikan (termasuk guru) untuk lebih apresiatif dan proaktif dalam memaksimalkan potensi pendidikan. Kedua, memberikan kesempatan luas kepada peserta didik dalam memanfaatkan setiap potensi yang ada, yang dapat diperoleh dari sumber-sumber yang tidak terbatas".

Salah satu teknologi yang dipakai dalam pendidikan yaitu internet. Internet menyimpan informasi yang tak terbatas yang dapat digunakan dalam belajar oleh peserta didk. Palmer W. Agnew dkk (dalam Deni, 2015: 27) menjelaskan bahwa pemanfaatan internet secara efektif dan efisien akan meningkatkan prestasi belajar peserta didik. Namun bila internet tidak dimafaatkan dengan bijak oleh peserta didik maka internet akan membawa efek negatif bagi peserta didik. Sholikah \& Saifudin (2013: 48) mengungkapkan bahwa Penggunaan internet khususnya situs jejaring sosial tentu akan memberikan dampak positif dan dampak negatif dalam dunia pendidikan. Kegiatan siswa dalam mengakses jejaring sosial akan menjadi 
kegiatan yang memicu turunnya motivasi belajar apabila digunakan pada saat jam pelajaran sedang berlangsung dan kegiatan mengakses jejaring sosial dikatakan tidak menyebabkan dampak menurunnya motivasi belajar apabila siswa menggunakan jejaring sosial pada waktu siswa dalam keadaan tidak terikat dalam suatu kondisi belajar dikelas maupun di rumah.

Berbeda dengan orang dewasa yang telah mampu memfilter hal buruk dan baik di internet, siswa yang masih tergolong remaja belum mampu memilah aktifitas internet yang bermanfaat dan mereka juga mudah terpengaruh oleh lingkungan sosial tanpa mempertimbangkan terlebih dahulu efek negatif dan positif yang akan diterima saat mengakses internet (Santoso S Hamidjoyo, 2011:29).

Pengaruh negatif yang paling berbahaya dari penggunaan internet yaitu menjadikan penggunanya kecanduan. Hal ini banyak kita temukan saat ini di sekeliling kita bahkan mungkin diri kita sendiri, yang tidak bisa lepas dari gadget dengan berbagai aplikasi sosial media didalamnya. Kecanduan menggunakan gadget tersebut juga dialami pelajar di sekolah dari tingkat sekolah dasar sampai dengan perguruan tinggi tanpa mengenal jenis kelamin.

Pelajar yang keasikan menggunakan internet seringkali menjadikan mereka malas bahkan lupa terhadap tugas dan tanggung jawab mereka, yaitu belajar. Kondisi seperti ini, penggunaan internet dapat mempengaruhi konsentrasi dan prestasi belajar siswa, kecuali bagi mereka yang memanfaatkan internet dengan tepat guna.Robin dan Linda (dalam Deni, 2015: 28), menjelaskan bahwa kecenderungan pemanfaatan media internet oleh setiap anak didik, bukan hanya dituntut pada perilaku anak didik tersebut menggunakan media internet tanpa menyalahgunakan situs didalamnya, tetapi mengenai keaktifan setiap peserta didik untuk mengakses internet sesuai kebutuhan kreatifitas pembelajaran.

Disisi lain penggunaan internet bagi peserta didik pada saat ini tidak bisa dipisahkan. Saat ini banyak sekali fasilitas internet yang bisa digunakan untuk belajar, sepesti mendownload buku pelajaran, menonton video pembelajaran, berbagi bahan pembelajaran dan banyak lagi fungsi lainnya, karena memang penggunaan internet dalam belajar memang lebih mudah dan efisien pada saat ini. Adanya internet ini diharapkan mampu meningkatkan hasil belajar siswa karena 
banyak sekali kemudahan belajar dengan menggunakan internet tersebut. Internet merupakan alat yang lebih mudah dan menyenangkan untuk mencari sumber belajar dan internet tentunya bisa dimanfaatkan sebagai media untuk meningkatkan minat belajar siswa agar prestasi mereka bisa meningkat (Deni, 2015: 35).

Namun apakah benar dengan adanya internet ini akan memberikan pengaruh positif pada prestasi belajar siswa di sekolah? Fenomena yang ditemukan oleh peneliti di SMA Negeri 13 Kerinci melalui observasi dan wawancara pada guru BK yang peneliti lakukan mendapatkan bahwa siswa di sekolah tersebut sudah dilarang oleh pihak sekolah untuk membawa Gadget mereka ke sekolah, namun peraturan tersebut sering dilanggar oleh siswa. Banyak siswa yang kedapatan bermain Gadget mereka ketika pelajara berlangsung, hasil wawancara dengan wali kelas bahwa dengan adanya internet di gadget siswa justru membuat siswa menjadi tidak berkonsentrasi dan ada juga yang mengantuk ketika proses belajar karena semalaman bermain gadget. Selain itu berdasarkan data nilai asli ujian MID semester genap 2016/2017 pada kelas XI IPA rata-rata siswa tidak mencapai nilai KKM, terutama pada mata pelajaran Matematika, Bahasa Inggris, dan Fisika. Dimana KKM yang di tetapkan adalah 7,00 sedangkan capaian siswa hanya 6,00 beberapa siswa bahkan memiliki nilai yang lebih rendah lagi.

Kemudian berdasarkan hasil wawancara dengan beberapa siswa di dapatkan informasi bahwa gadget yang mereka miliki memiliki beberapa aplikasi sosial media seperti facebook, Instagram, whatsap, dan beberapa game online yang mereka gunaka setiap harinya dengan intensitas yang tinggi.

Berdasarkan fenomena yang dipaparkan tersebut, peneliti tertarik untuk mencari tahu bagaimana pengaruh intensitas penggunaan internet terhadap hasil belajar siswa di SMA Negeri 13 Kerinci. Dimana peneliti akan mendeskripsikan bagaimana intensitas penggunaan internet pada siswa dan pengaruhnya terhadap prestasi belajar yang dimiliki oleh siswa di SMA Negeri 13 Kerinci. Diharapkan penelitian ini dapat beranfaat bagi pengembangan ilmu dan pertimbangan dalam pengambilan keputusan bagi pihak terkait. 


\section{METODOLOGI}

Penelitian ini menggunakan metode kuantitatif jenis deskriptif untuk mendesripsikan keadaan intensitas penggunaan internet pada siswa dan deskriptif korelasional untuk menguji hipotesa penelitian. Pembuktian atas hipotesa dilakukan untuk membuktikan apakah intensitas penggunaan internet berpengaruh terhadap prestasi belajar siswa atau tidak adanya pengaruh sama sekali. Dalam penelitian ini hipotesis yang diajukan oleh peneliti berdasarkan studi literatur yang telah dilakukan yaitu "Terdapat hubungan negatif yang signifikan antara intensitas penggunaan internet dan hasil belajar siswa, dimana semakin tinggi tingkat intensitas penggunaan internet oleh siswa maka akan semakin rendah hasil belajar yang dimiliki oleh siswa tesebut".

Populasi dalam penelitian ini adalah seluruh siswa SMA Negeri 13 Kerinci tahun ajaran 2017/2018 dengan jumlah 284 siswa yang memiliki perbedaan jumlah di setiap tingkatannya. Sampel diambil dengan menggunakan teknik Proportional Random Samplingtujuannya agar jumlah sampel disetiap strata sebanding dengan jumlah anggota pada populasi. Sampel diambil dengan derajat kesalahan 0,05 maka diperoleh sampel sebanyak 166 orang siswa, dengan rincian kelas X sebanyak 53 orang, kelas XI sebanyak 52 dan Kelas XII sebanyak 60 orang siswa.

Instrumen penelitian untuk mengukurvariabel intensitas pengguanaan internet pada siswa digunakan angket dengan skala likert. Sebelum disebarkan intrumen telah diuji cobakan, yaitu uji validitas dan uji reliabilitas sehingga diperoleh instrument dengan butir soal sebanyak 22 buah dan reliabel keseluruhan sebesar 0,888. Teknik analisis data yang digunakan adalah teknik persentase dan rumus korelasi. Kemudian untuk variabel prestasi belajar akan dikumpulkan data nilai ujian tengah semester genap siswa.

\section{HASIL PENELITIAN}

\section{Deskripsi Data}

Data dalam penelitian ini akan dideskripsikan keadaan intensitas penggunaan internet oleh siswa di SMA Negeri 13 Kerinci dengan jumlah sampel sebanyak 
165 orang siswa. Adapun gambaran tingkat intensitas penggunaan internet oleh siswa di SMA Negeri 13 Kerinci dapat dilihat pada tabel 1 di bawah ini.

Tabel 1. Kategori Intensitas Penggunaan Internet oleh Siswa

\begin{tabular}{|c|l|c|c|}
\hline No & Kategori & f & $\%$ \\
\hline 1 & Rendah & 0 & 0 \\
\hline 2 & Cukup & 0 & 0 \\
\hline 3 & Sedang & 64 & 38,78 \\
\hline 4 & Tinggi & 101 & 61,21 \\
\hline 5 & Sangat tinggi & 0 & 0 \\
\hline
\end{tabular}

Berdasarkan tabel satu di atas, diperoleh data bahwa intensitas penggunaan Internet di SMA Negeri 13 Kerinci masuk pada kategori tinggi dengan 61,21\% dan kategori sedang dengan presentase 38,78\%. Untuk melihat distribusi data subvariabel maka akan dipaparkan pada tabel 2 berikut ini.

Tabel 2. Distribusi Data Intensitas Penggunaan Internet oleh Siswa berdasarkan Subvariabel

\begin{tabular}{|c|c|c|c|c|c|c|}
\hline \multirow{2}{*}{ No } & \multirow{2}{*}{ Subvariabel } & \multicolumn{5}{|c|}{ Skor jawaban (\%) } \\
\hline & & SL & SR & KD & JR & TP \\
\hline 1 & $\begin{array}{l}\text { Internet } \\
\text { digunakan } \\
\text { sebagai media } \\
\text { komunikasi }\end{array}$ & 6,96 & 20 & 20,2 & 33,3 & 11 \\
\hline 2 & $\begin{array}{l}\text { Internet } \\
\text { digunakan } \\
\text { sebagai media } \\
\text { pertukaran } \\
\text { data } \\
\end{array}$ & 5,15 & 20,9 & 25,1 & 28,1 & $\begin{array}{c}20 \\
6\end{array}$ \\
\hline 3 & $\begin{array}{l}\text { Internet } \\
\text { digunakan } \\
\text { sebagai media } \\
\text { memperoleh } \\
\text { informasi }\end{array}$ & 15,1 & 49,6 & 32,1 & 1,81 & $\begin{array}{c}1,2 \\
1\end{array}$ \\
\hline 4 & $\begin{array}{l}\text { Internet } \\
\text { digunakan } \\
\text { untuk } \\
\text { membentuk } \\
\text { komunitas }\end{array}$ & 12,3 & 32,3 & 30 & 18,7 & $\begin{array}{c}6,2 \\
5\end{array}$ \\
\hline
\end{tabular}


Berdasarkan tabel 2 tersebut dapat diketahui bahwa intensitas penggunaan internet yang digunakan sebagai media komunikasi tergolong sering (20\%) dan kadang-kadang (20,2\%). Kemudian intensitas penggunaan intenet yang digunakan sebagai media pertukaran data yaitu kadang-kada $(25,1 \%)$. Kemudian internet yang digunakan sebagai media memperoleh informasi yaitu sering $(49,6 \%)$. Kemudian untuk membentuk komunitas yaitu sering $(32,3 \%)$ dan yang terakhir internet membuat banjir informasi siswa menjawab kadang-kadang $(45,6 \%)$.

Untuk deskripsi prestasi belajar siswa maka dapat dilihat pada tabel 3 berikut ini.

Tabel 3. Distribusi Data Prestasi belajar siswa.

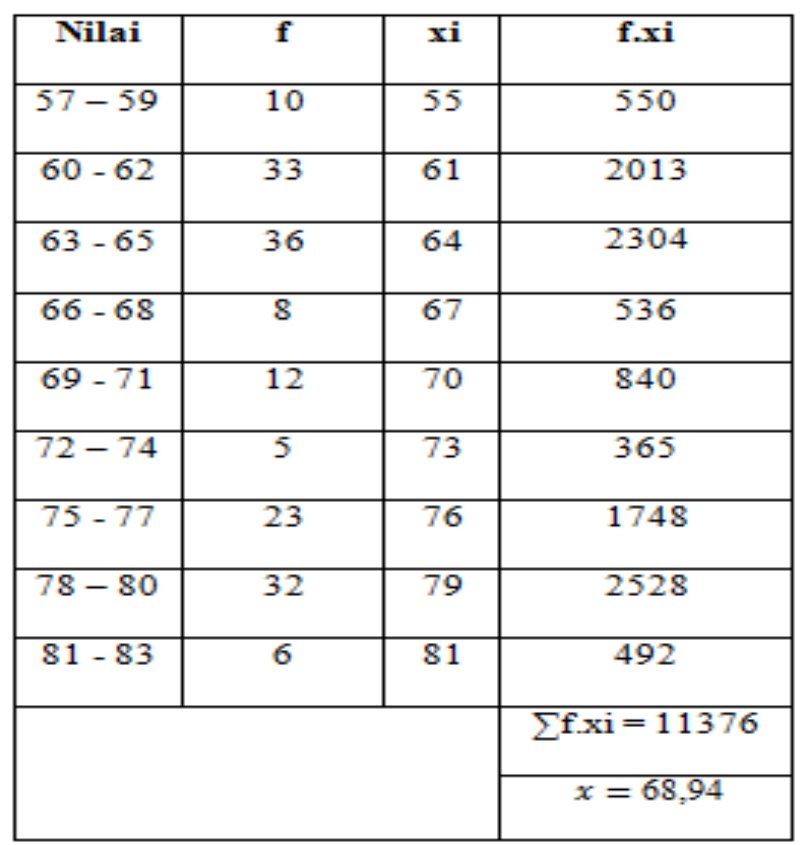

Berdasarkan tabel di atas, dapat dilihat bahwa rata-rata prestasi belajar siswa adalah 68,94 yang menunjukkan prestasi belajar siswa berada pada kategori rendah.

\section{Uji Hipotesis}

Dalam penelitian ini terdapat hipotesi yang diuji kebenarannya. Berikut merupakan paparan hasil uj hipotesis penelitian, yang dapat dilihat pada tabel 4 berikut ini. 
Tabel 4. Hasil Uji Hipotesis

\begin{tabular}{|rl|r|r|}
\hline & \multicolumn{1}{c|}{ Correlations } \\
\hline \multirow{4}{*}{$\mathrm{x} \quad$ Pearson } & \multicolumn{1}{c|}{$\mathrm{y}$} \\
\hline & Correlation & 1 & .141 \\
& Sig. (2-tailed) & & .071 \\
$\mathrm{~N}$ & 165 & 165 \\
& Pearson & -.141 & 1 \\
$\mathrm{y} \quad$ Correlation & .071 & \\
& Sig. (2-tailed) & 165 & 165 \\
$\mathrm{~N}$ &
\end{tabular}

Dari tabel 4 di atas, dapat diketahui bahawa hasil ui hipotesis menunjukkan bahwa adanya pengaruh intensitas penggunaan internet terhadap prestasi belajar siswa di SMA Negeri 13 Kerinci yaitu -0,141. Artinya adanya pengaruh negatif yang signifikan antara intensitas penggunaan internet terhadap prestasi belajar siswa dan terjadinya hubungan timbal balik variabel $\mathrm{x}$ dan variabel $\mathrm{y}$, dimana tingginya intensitas penggunaan internet, maka semakin rendah prestasi belajar siswa. Besarnya pengaruh negatif intensitas penggunan internet terhadap prestasi belajar siswa memberikan kontribusi sebesar 14,1\%. Artinya bahwa Hipotesis diterima.

\section{PEMBAHASAN}

Berdasarkan hasil penelitian maka dapat diketahui bahwa intensitas penggunaan internet yang dilakukan oleh siswa tergolong pada kategori Tinggi dengan persentase sebesar $64,21 \%$. Para siswa banyak mengunakan internet untuk media komunikasi dengan persentase tertinggi yaitu 33,3\%. Hal ini sesuai dengan pernyataan Astrid S. Susanto (dalam Chairunnisa, 2010: 35) bahwa "Hakekat internet adalah alat yang digunakan sebagai media untuk menyampaikan pesan dari satu orang ke orang lain".

Selain itu internet juga digunakan sebagai alat untuk pertukaran data oleh siswa. Namun persentase tertinggi siswa menyatakan jarang melakukan pertukaran data yaitu sebanyak $48,48 \%$. Keadaan ini sangatlah disarankan, karena 
kurang dimanfaatkannya internet oleh siswa untuk media pertukaran data oleh siswa. Priyatno (2014: 60) menyatakan bahwa "internet memungkinkan semua orang untuk saling bertukaran data”. Data yang dimaksud dalam hal ini adalah data pembelajaran seperti Video pembelajaran dan bahan-bahan bacaan, buku online yang jarang dishare oleh siswa.

Dari data tersebut dapat dianalisis bahwa penggunaan internet oleh siswa di SMA Negeri 13 Kerinci yang tergolong tinggi ini ternyata lebih banyak digunakan sebagai alat komunikasi dan pembentukan komunitas. Justru fungsi positif internet bagi pelajar masih terbilang rendah pemanfaatannya oleh siswa. Seperti berbagi informasi tentang pelajaran dengan mengguanakan internet. Hal inilah yang menjadi salah satu alasan bahwa intensitas penggunaan internet yang tinggi justru membuat prestasi belajar menurun, sesuai dengah hasi uji hipotesis yang dilakukan. Hasil penelitian ini didukung teori yang dikemukakan oleh Aji Supriyanto (2005: 338) yang menyatakan bahwa sebagai pusat pembelajaran dan pendidikan, internet sangat kaya akan informasi tentang ilmu pengetahuan, teknologi dan informasi lainnya yang menjadikan internet sangat terkenal pula sebagai perpustakaan digital (digital library), namun Pemanfaatan internet yang dilakukan siswa dalam pembelajaran apabila dilakukan kurang maksimal maka dapat menurunkan prestasi belajar mereka.

Pada dasarnya internet memiliki kegunaan yang sangat banyak bagi para pelajar, bila penggunaanya bertujuan untuk membantu kegiatan belajar dan mencari informasi tentang pembelajaran. Menurut priyatno (2014: 23) Adapun beberapa dampak positif dari penggunaan internet sebagai berikut:

Internet sebagai media komunikasi, merupakan fungsi internet yang paling banyak digunakan dimana setiap pengguna internet para pengguna dapat berkomunikasi dengan pengguna lainnya dari seluruh dunia.

1. Media pertukaran data, dengan menggunaka email, newsgroup, ftp dan www (world wide web)para pengguna internetdiseluruh dunia dapat saling bertukar informasi dengan cepat dan mudah.

2. Media untuk mencari informasi atau data, perkembangan internet yang pesat, menjadikan $w w w$ sebagai salah satu sumber informasi yang penting dan akurat 
3. Fungsi komunitas, internet membentuk masyarakat baru yang beranggotakan para pengguna internet dari seluruh dunia.

Supriyanto (2005) mengemukakan bahwa sebagai pusat pembelajaran dan pendidikan, internet sangat kaya akan informasi tentang ilmu pengetahuan, teknologi, dan informasi lainnya yang menjadikan internet sangat terkenal pula sebagai perpustakaan digital(digital library)". Oleh karena itu, Guru sebagai motivator dan dinamisator dalampembelajaran hendaknya memberi dorongan serta menciptakan kondisi agarsiswa dapat secara aktif menemukan ilmu pengetahuan baru melaluipemanfaatan teknologi internet. Selain sumber belajar berupa perpustakaanyang tersedia di sekolah, sekarang ini berkembang teknologi internet yangmemberikan kemudahan dan keleluasaan dalam menggali ilmu pengetahuan.

Melihat banyaknya fungsi positif dari internet tersebut hendaknya siswa mampu memanfaatkannya dengan baik. Namun bila internet digunakan oleh siswa hanya untuk bersosial media dan bermain game hingga kecanduan maka internet ini akan menjadi bumerang bagi para pelajar. Di SMA Negeri 13 Kerinci kecanduan internet yang dimanfaatkan siswa bukan sebagai sarana belajar menyebabkan semakin buruknya prestasi belajar yang dimiliki oleh siswa.

Prestasi belajar sangat diutamakan dalam dunia pendidikan. Prestasi dapat diartikan sebagai hasil yang diperoleh karena adanya aktivitas belajar yang dilakukan, karena pada prinsipnya setiap orang yang melakukan proses belajar akan mengalami suatu perubahan dalam dirinya. Winkel (1989: 50), menyatakan bahwa "prestasi merupakan hasil usaha yang dilakukan dan menghasilkan perubahan yang dinyatakan dalam bentuk simbol untuk menunjukkan kemampuan pencapaian dalam hasil kerja dalam waktu tertentu". Keadaan prestasi blajar yang rendah tentunya dipengaruhi oleh banyak faktor, namun hasil penelitian yang memperlihatkan intensitas penggunaan internet yang digunakan bukan sebagai bahan belajar menyumbang sebesar $14,1 \%$ dalam menurunnya hasil belajar siswa di SMA Negeri 13 Kerinci. 
JUANG: Jurnal Wahana Konseling (Vol. 2, No. 1, Maret 2019)

\section{KESIMPULAN DAN SARAN \\ KESIMPULAN}

Berdasarkan temuan dan pembahasan hasil penelitian, dapat dikemukakan kesimpulan sebagai berikut.

1. Intensitas penggunaan internet pada siswa di SMA Negeri 13 Kerinci tergolon tinggi dengan persentase $61,21 \%$.

2. Terdapat pengaruh negatif yang signifikan antara intensitas penggunaan internet terhadap prestasi belajar siswa dan terjadinya hubungan timbal balik variabel x dan variabel y, dimana tingginya intensitas penggunaan internet, maka semakin rendah prestasi belajar siswa. Besarnya pengaruh negatif intensitas penggunan internet terhadap prestasi belajar siswa memberikan kontribusi sebesar $14,1 \%$.

\section{SARAN}

Berdasarkan hasil penelitian yang diperoleh maka dapat diberikan saran sebagai berikut:

1. Guru BK hendaknya mampu bekerjasama dengan guru mata pelajaran dalam membantu peserta didik menggunakan internet dengan tepatguna, agar penggunaan internet pada siswa meningkatkan hasil belajar siswa bukan malah menurunkan hasil belajar siswa.

2. Bagi siswa Hendaknya dengan majunya teknologi internet, dapat membantu siswa memepermudah mencari referensi pembelajaran sehingga prestasi belajar siswa dapat lebih meningkat.

3. Bagi pihak terkait seperti dinas pendidikan dan kepala sekolah SMA Negeri 13 Kerinci hendaknya membuat semacam program penyuluhan pada siswa tentang penggunaan internet yang sehat sebagai bahan belajar di SMA Negeri 13 Kerinci, karena siswa yang kecanduan internet untuk hal lain selain penunjang pembelajaran tersebut mungkin kurang mengetahui fungsi internet yang mampu mempermudah dalam belajar. 
JUANG: Jurnal Wahana Konseling (Vol. 2, No. 1, Maret 2019)

\section{DAFTAR RUJUKAN}

Arikunto, Suharsimi. 2007. Managemen Penelitian. Jakarta. Rineka Cipta.

Chairunnisa. 2010. Hubungan intensitas mengakses facabook dengan motivasi belajar siswa MAN 13 Jakarta. Skripsi: Universitas Islam Nwgeri Syarif Hidayatul.

Deni, Darmawan. 2015. Teknologi Pembelajaran. Bandung: Remaja Rosdakarya.

Prayitno. 2014. Multimedia Komunikasi. Jakarta: Elekmedia Komputindo.

Santoso, Hamidjoyo. 2011. Pembelajaran berbasis teknologi. Bandung: UPI.

Sholikah dan shaifuin. 2013. Media Komunikasi. Yogyakarta: Andi Offset.

Slameto. 2003. Belajar dan Faktor yang mempengaruhinya. Jakarta: Rineka Cipta.

Supriyanto, Agus. 2009. Cooperative Learning Theori dan Paikem. Yogyakarta: Pustaka Belajar.

Susilowati. 2014. Pengaruh intensitas penggunaan facebook terhadap prestasi belajar pendidikan pancasila dan kewarganegaraan siswa XI di SMA negeri Slahung. Journal Fakultas Ilmu tarbiyah dan keguruan UIN sunan kalijaga, diakses dalam www.diligligundip.ac.id .

Winkel, WS. 1989. Psikologi Pembelajaran. Jakarta: Gramedia.

Yusuf, A. Muri. 2013. Penelitian Kuantitatif, kualitatif dan enelitian gabungan. Padang: UNP Prees. 